\title{
Custodians of Morality, Motherhood, and Whiteness: Sex Education for Girls in American Schools During the Early 1920s
}

\author{
Emily Tran
}

In the aftermath of the First World War, the United States Public Health Service inaugurated its first sex education curriculum for American schoolchildren. This essay examines context surrounding the emergence of the earliest sex education curricula in the United States, and offers and analysis of the United States Public Health Service's 1922 publication High Schools and Sex Education: A Manual of Suggestions on Education Related to Sex. I suggest that, in a period marked by progressivism and women's gains in the workplace and in their social lives, this sex education curricular guide asserted that schoolgirls should learn that they were responsible for the sexual behaviour - and misbehaviour - of men and boys, that their sexual lives were entries into their sacred social role as wives and mothers, and that their sexual behaviour bore important implications for the continued vitality of the white race

On 23 November 1918, weeks after the First World War ended, Charles W. Eliot, President Emeritus of Harvard University, delivered a lecture at Carnegie Hall in New York City on the "Defects in American Education Revealed by the War."1 In the speech, Eliot described the capacities in which American soldiers and the United States at large had been found wanting during the war, such as literacy, nutrition, cleanliness, infant mortality, tuberculosis, and scientific training, and he proposed reforms in education to address these inadequacies. Listed second only to the problem of illiteracy was "the prevalence of venereal disease" as revealed in the military draft, "to a degree which has appalled the entire people." To combat the spread of these "terribly destructive diseases" both in the military and in American society more broadly, Eliot suggested that a national public health service be established, and that "all American schools, churches, [and] religious organizations" be enlisted in the important work of "permanently reduc[ing] or restrict[ing]" venereal diseases through "every possible educational influence which the entire community can exert.", Eliot's 1918 call to action regarding venereal disease was

\footnotetext{
${ }^{1}$ Eliot's lecture was published in its entirety in the New York Times the next day. Charles W. Eliot, "Defects in American Education Revealed by the War," New York Times, 24 November 1918.

2 Eliot, "Defects in American Education."
} 
timely. That same year, the United States Public Health Service began a decade-long education program to combat venereal disease that saw sex education enter homes, schools, churches, and community organizations as the federal government attempted to re-shape sexual behaviour and the family through public health initiatives. ${ }^{3}$

This paper examines the role of the U.S. Public Health Service in the emergence of sex education in American schools during the early twentieth century in the aftermath of the First World War. In particular, I examine the portrayal of girls and women and their roles in the sex education curriculum suggested by the Public Health Service (PHS) to high school administrators and teachers. I will briefly outline the social, political, and cultural context of the emergence of sex education in the U.S. during the post-World War I years. Then, I will examine a 1922 curricular guideline on sex education in high schools, High Schools and Sex Education: A Manual of Suggestions on Education Related to Sex, which was jointly created by the office of the Surgeon General of the U.S. Public Health Service and the federal Bureau of Education. ${ }^{4}$ Ultimately, this analysis demonstrates that, under the U.S. Public Health Service's prescribed curriculum, girls were to learn that they were responsible for the sexual behaviour - and misbehaviour - of men and boys, that their sexual lives were entries into their sacred social role as wives and mothers, and that their sexual behaviour bore important implications for the continued vitality of the white race. As Charles W. Eliot indicated in his November 1918 speech, a major impetus for the federal effort in sex education during the post-WWI years was the national panic that had resulted from reports of high rates of venereal disease among army enlistees and soldiers. During the war, the U.S. Congress created the Interdepartmental Social Hygiene Board, which included the Secretary of the Treasury, the Secretary of War, the Secretary of the Navy, and representatives of the U.S. Public Health Service and Army and Navy Medical Corps, to address the problem in the armed forces. ${ }^{5}$ In addition to the U.S. military's reports of high venereal disease rates among enlisted men, the emergence of the Wasserman Test in the 1920s provided further medical validation for concern about Americans' sexual behaviour. The test enabled physicians to diagnose syphilis, and the ability to detect cases that may have previously been overlooked which, along with the test's high rate of false positives, further contributed to the perception that the nation

${ }^{3}$ Alexandra M. Lord, “'Naturally Clean and Wholesome': Women, Sex Education, and the United States Public Health Service, 1918-1928," Social History of Medicine 17, no. 3 (December 2004): 424.

${ }^{4}$ The question of children's classroom experiences of sex education is compelling, but would require deeper research into sources, such as state-level curricular guidelines, Parent Teacher Association meeting minutes, former teachers' personal papers, and former students' personal papers. Instead, this analysis focuses on what federal PHS officials thought children should learn about sex and sexuality in U.S. high schools.

${ }^{5}$ Jonathan Zimmerman, Too Hot to Handle: A Global History of Sex Education (Princeton: Princeton University Press, 2015), 20. Another impact of the military and the First World War on postwar sex education efforts was in language. In "Naturally Clean and Wholesome," Lord examines the use of war imagery and rhetoric in PHS publications on venereal disease, pp. 437. 
faced a major epidemic of venereal disease. ${ }^{6}$

Concern for the sexual morality of Americans in the post-WWI era was rooted not only in medical evidence, but also wider demographic, social, and cultural changes in the United States. Urbanization and the rapid growth of cities had brought an increase in prostitution as a form of recreational sex for middle-class men and employment for poor women, thus resulting in higher risk of syphilis and gonorrhoea for both populations. ${ }^{7}$ In addition, a massive wave of immigration between 1880 and 1920 engendered defensiveness on the part of many white native-born Americans, who came to view their white American culture as "under attack" by sexually promiscuous and immoral immigrants. As historian Alexandra M. Lord has indicated, though many immigrant girls were in fact prostitutes, this was due to economic impoverishment rather than the inherent immorality of immigrant cultures. ${ }^{8}$ In addition to immigrants from abroad, white native-born Americans also feared African American migrants moving from the rural south into northern cities at the outset of the Great Migration. White Americans' fears of African American culture and immorality took a racialized and gendered form, echoing long-established white fears that the purity of white daughters would be preyed upon by sexually promiscuous and predatory black men. ${ }^{9}$ As Lord argues, early twentieth-century public sex education campaigns offered to white native-born Americans the opportunity to "Americanize" and civilize vulgar and lesser immigrant and African American groups by educating them on the dangers of sexual promiscuity and the importance of sexual self-control. ${ }^{10}$

Another source of alarm and discontent during the turn of the century and the postwar era that contributed to fears about sexual morality of the American populace was the changing role of women. Larger numbers of women entered the workforce as teachers, secretaries, social workers, and nurses, earning increased independence and challenging established gender roles. ${ }^{11}$ Women's increased economic autonomy outside of the home through participation in the labour force was matched by their increased agency in their personal lives and relationships. Working-class women and men engaged in "treating," whereby young men, who earned higher wages, would offer gifts to young women in

${ }^{6}$ Lord, "Naturally Clean and Wholesome," 427.

${ }^{7}$ John L. Rury, “'We Teach the Girl Repression, and the Boy Expression': Sexuality, Sex Equity and Education in Historical Perspective, Peabody Journal of Education 64, no. 4 (Summer 1987): 53.

${ }^{8}$ Alexandra M. Lord, Condom Nation: The U.S. Government's Sex Education Campaign from World War I to the Internet (Baltimore: The Johns Hopkins University Press, 2010), 15-17. Lord also discusses the widespread rumours of "white slavers," that is, immigrant men who lured white native-born women into prostitution, as another product of nativist concerns during this era.

${ }^{9}$ Lord, Condom Nation, 34.

${ }^{10}$ Lord, Condom Nation, 17 and 34. Lord also discusses the emergence of Jim Crow and the effects thereof on white notions of African American sexual impropriety and danger on p. 17.

${ }^{11}$ Rury, "We Teach the Girl Repression," 52. 
return for sexual favours. In the 1910s and 1920s, dating among middle and upper class youth altered courtship patterns and removed daughters from the realm of parental supervision. Both of these developments in young people's social and sexual relationships resulted in fewer social controls on their behaviour, and anxiety that women were either challenging sexual boundaries or risking sexual impropriety and venereal disease. $^{12}$

That Americans would turn to schools and public education institutions to address the problem of venereal disease and sexual morality during the early twentieth century can be understood as a product of the political context of the period, which has since been dubbed the Progressive Era. The period, running from the 1890s through the 1920s, saw reformers and political movements that called for increased government intervention to better the lives of working-class Americans, and resulted in legislation on child labour, alcohol prohibition, and industry regulation, among others. ${ }^{13}$ Another product of the Progressive Era was the dramatic expansion of public schooling. Education historian Jonathan Zimmerman has argued that school-based sex education took root in the United States earlier than in Europe because the U.S. invested in public education earlier than most other countries, and more readily looked to schools as a solution to social ills. In addition, the United States sent comparatively more adolescents to secondary school, where sex education was most often taught, thus rendering schools as a suitable venue for public education efforts on sexuality and sexual health. Sex education in schools thus not only fit with progressive reformers' affinity for government-sponsored social hygiene efforts, but also reflected the Progressive Era belief in public schools as institutions for the betterment of American society. ${ }^{14}$

Many of the medical, social, demographic, and political concerns of the early twentieth century emerged in some way in the Public Health Service's 1922 curricular guideline, High Schools and Sex Education: A Manual of Suggestions on Education Related to Sex. Intended to aid the high school teachers and principals, the guide featured descriptions of classroom sex education activities practiced in high schools across the country, responses to questionnaires by the Bureau of Education and the PHS, and addressed commonly raised questions at sex education conferences. ${ }^{15}$ Pointing to the "widest social importance" of sex education for its impact on the attitudes and practices of individuals in their relationships with others, the guide urged that sex education be integrated "as an organic part of the entire educational program, and not be considered a special and

\footnotetext{
${ }^{12}$ Lord, "Naturally Clean and Wholesome," 425-426.

${ }^{13}$ Lord, Condom Nation, 13.

${ }^{14}$ Zimmerman, Too Hot to Handle, 16.

${ }^{15}$ United States Public Health Service [hereafter PHS], High Schools and Sex Education: A Manual of Suggestions on Education Related to Sex (Washington, D.C., Government Printing Office, 1922), v.
} 
isolated bit of ritual to be performed at a given time, and then dismissed as finished."16 To that end, the guide's editors organized the book by classroom subject, with each chapter offering suggestions of how to incorporate sex education into, for instance, biology, physical education, social studies, and English classes. My analysis focuses on the advice offered in the chapter on home economics. ${ }^{17}$ As noted in High Schools and Sex Education, home economics classes were especially valuable venues for sex education as they offered "established segregation of the sexes," and "intimate personal relations between teachers and pupils," thus allowing for a more candid discussion of female sexuality with the girls. ${ }^{18}$

In the chapter of High Schools and Sex Education focused on an environment in which female students would be taught alone, the guideline instructed teachers to convey three broad messages regarding women's responsibilities in their sexual lives. The first was a responsibility for the behaviour of boys and men. In contrast to a cultural context in which treating and dating gave young women a sense of autonomy, choice, and reciprocity in their personal relationships with young men, the PHS sex education guidelines taught girls that while boys could and should express their sexuality, girls should repress their sexuality for the good of boys and men, who were otherwise helpless in controlling their carnal desires. For instance, home economics teachers were advised to add to their sewing classes a discussion of "the effects upon the feelings produced by color and line, and of various purposes which garment design can be made to serve, and the corresponding responsibilities involved in the selection and designing of dress." 19 Arguably, the implicit suggestion of this guideline was that women, as dressmakers and in everyday life, should take care to sew modest silhouettes and dress simply so as not to irresponsibly provoke the sexual desires of men.

Women's responsibility for controlling male sexuality also extended to an expectation that they should learn how to care for those with venereal diseases. Following a lesson on "microorganisms, ... . how they are transferred from one person to another, . . . [and] the subject of disease," girls were to learn basic nursing duties in caring for the sick. In addition to "bathing, bed making, daily routine care of the patient, [and] simple treatments" class time was to be devoted to "a talk on disease symptoms and how they might be recognized, in order that the disease may be reported to a doctor in the earliest

\footnotetext{
${ }_{17}^{16}$ PHS, High Schools and Sex Education, 2.

17 As education historian John L. Rury has noted, the beginning of the twentieth century marked "a new era in women's education," as educators devised female-oriented curricula such as home economics class to "guarantee that [women] would not lose touch with traditionally female roles" as more and more women entered the workforce. Rury, "We Teach the Girl Repression," 53.

18 PHS, High Schools and Sex Education, 57.

${ }^{19}$ PHS, High Schools and Sex Education, 58.
} 
possible stage. ${ }^{20}$ Though not explicitly stated, the positioning of this lesson on nursing and identifying disease after a lesson on transmittable disease, and the fact that High Schools and Sex Education was focused, as the title suggests, on sex education, it is reasonable to assume that the diseases girls were to learn how to treat were venereal diseases. Thus, the PHS wished for young women to be taught that they were responsible not only for psychological sexual impulses of men, but for the medical consequences of venereal diseases.

Though young women's responsibility for the control of male sexuality was implicit in the home economics lessons on sewing and nursing, High Schools and Sex Education also bluntly stated young women's culpability for the sexual impulses of men. After a lesson for grade nine students on reproduction, which focused heavily on plant and animal reproduction, ${ }^{21}$ the guide exhorted teachers to "impress upon the girls the importance of so conducting themselves to insure the best influence upon the thoughts of their boyfriends." In particular, young women were to be "modest and dignified" in behaviour, and model "high ideals of conduct." The PHS thus tied young women's proper behaviour to its effect on young men - young women should be modest and dignified so as to set a standard that boys, inherently weak, could emulate. In this way, young women's sexual behaviour was portrayed as a means to an end. Their behaviour, dress, and abilities were useful only so far as they restrained the sexual impulses of young men. The PHS further extended young women's realm of influence by affirming that their behaviour would "make for happier and healthier living, [and] contribute to the character and welfare of those with whom [the girls] come in touch." ${ }^{22}$ In casting young women as models of proper behaviour and morality who bestowed good influence on all those around them, the PHS alluded to the traditional gender role of women as passive nurturers and caregivers, devoid of sexual desire.

High Schools and Sex Education similarly stated the accountability of young women for the behaviour of the men around them in a suggested curriculum for students in grade twelve. Following a discussion on "immoral tendencies in dress, dancing, the theater, literature, and art," teachers were to discuss "the general behaviour of the girl with her boy and men friends," with particular emphasis on "her responsibility for their welfare." "The boy looks to the girl for his ideals;" the PHS guide explained, "he goes as far as she allows him to go." Here, young women were deemed not only responsible for the

${ }^{20}$ PHS, High Schools and Sex Education, 59.

${ }^{21}$ Zimmerman notes in Too Hot to Handle that during the first decades of the twentieth century, western nations largely shared this approach to sex education that "us[ed] models and metaphors from the animal world." Zimmerman, Too Hot to Handle, 15.

${ }^{22}$ PHS, High Schools and Sex Education, 60. 
"welfare" of peer-group boys and men older than them, but also blamed if a man were to stray off the path of righteous sexual behaviour, for no man would do so unless permitted by a woman. By infantilizing boys and men into individuals devoid of personal responsibility for their actions and any notion of morality save for that modeled by women, the PHS's guide implicitly excused men for their poor behaviour, and foisted all guilt on women, who supposedly enabled men's immorality. Indeed, the guide went on to caution girls to "regulate [their] behaviour accordingly, remembering that, if any wrong is done[,] the blame, whether rightly or wrongly, is always thrown on the woman.",23

The PHS's desire to teach young women that they were responsible for controlling the sexual impulses of the men around them built upon a highly stereotyped image of women as uplifting caregivers of the weak and vulnerable. High Schools and Sex Education forcefully emphasized this nurturing role of women by teaching young women that second to their present and future responsibility to control male sexuality was their responsibility as future wives and mothers. Addressing concerns that the inclusion of sex education might prove controversial and garner parental resistance, High Schools and Sex Education reassured teachers and school administrators that "when the nature of the course becomes known, and its constructive value for the careful preparation of the girl for true wifehood and motherhood is realized, parents are usually very grateful." ${ }^{24}$ The writers of the curricular guide further aligned sex education with preparation for motherhood by praising the "founder of the home economics movement" Dr. Ellen H. Richards, "who asked, 'Shall we train for future parents?" With Richards' guideline in mind, the PHS declared, "opportunities for the most difficult topics present themselves." 25 High Schools and Sex Education thus explicitly declared that sex education for girls was intended not to teach them about their own sexual health and sexuality, but to prepare them for parenthood. The purpose of sex, then, was to become a mother, and the curriculum for sex education should thus be centered on this assumed eventuality.

A key component of the PHS grade twelve and grade nine sex education curricula in home economics class was an emphasis on marriage and motherhood immediately following the lecture on reproduction. Students were to learn about "marriage; including the dangers of the secret and runaway marriage, care of the pregnant mother; [and] care of the baby." Using baby dolls, female students would practice "clothing, bathing, feeding (both natural and artificial)" infants. ${ }^{26}$ Historian Alexandra M. Lord has noted

\footnotetext{
${ }^{23}$ PHS, High Schools and Sex Education, 62.

${ }^{24}$ PHS, High Schools and Sex Education, 62.

${ }^{25}$ PHS, High Schools and Sex Education, 63.

${ }^{26}$ PHS, High Schools and Sex Education, 61.
} 
that the teaching of baby care in sex education classes constituted "scientific motherhood," and suggested that women's primary role as mothers was so paramount as to require expert advice in order that they might successfully perform motherhood. ${ }^{27}$ Additionally, the emphasis on "the dangers" of elopment suggests an intention to shape students' notions of family and social acceptability. In some cases, live babies could be brought into the classroom with their mothers. Such a demonstration, the PHS enthused, would "vitalize" the work of the girls, and "develop further cooperation of the homes.",28 By gaining direct experience with live children, it was hoped that high school girls in sex education class might realize the importance of their destiny as mothers; this in turn would strengthen parental approval of the sex education program.

Young women's responsibility to become mothers also carried a responsibility to protect their future children. In lecturing students on gonorrhoea and syphilis, the PHS instructed teachers to focus on "the more important effects on the wife mother and child." Indeed, female students were to realize "the grave importance of marrying a man who is free from both diseases." High Schools and Sex Education went on to warn female students that it was not just their potential husbands who could infect them and their future children with venereal disease. Students were to learn to be "more careful as to their choice of friends, and to take precautions in public toilets" in order to protect themselves from syphilis and gonorrhoea." 29 This declaration that venereal disease could spread in these ways was, of course, baseless. Young girls were thus taught not only that they had a responsibility to become wives and mothers, but that they must marry the right sort of man, and have the right sort of friends, and patronize the right sort of establishments in order to protect themselves and their hypothetical children from the ravages of venereal disease. Along with further encouraging young women to self- police their own behaviour, this enabled the PHS to frame the campaign against the venereal disease epidemic as a maternal issue to be taken on by women who wanted to protect their children and families.

The final responsibility the PHS sought to instill in young women through home economics class-based sex education was closely tied to girls' duty to become mothers and the notion that they must marry the right sort of spouse. Specifically, young white girls, to whom the curriculum was directed, bore a responsibility to strengthen the vitality of the white race through their sexual relationships and the offspring thereof. ${ }^{30}$ Historian Jonathan Zimmerman has described this eugenic objective as a "key arrow in sex

${ }^{27}$ Lord, "Naturally Clean and Wholesome," 437.

${ }^{28}$ PHS, High Schools and Sex Education, 59.

${ }^{29}$ PHS, High Schools and Sex Education, 62-63.

${ }^{30}$ Lord explores the African American reception to the U.S. Public Health Service's sex education programs in Condom Nation, 34-35. 
educators' avowedly scientific arsenal." "31 In High Schools and Sex Education, the supposed dangers of interracial relationships and miscegenation were never discussed in detail, but offhand references to race in the midst of discussions of other topics indicate the degree to which racial eugenic thinking had permeated American white society, so as not to even require explanation.

In outlining the PHS's aspirations for the sex education program in American high schools, the editors wrote of high school students, "We want them to have high ideals of personal responsibility - not merely with respect to property or contracts for goods and services, but also with respect to personal relations and especially with respect to race." The PHS continued, "We want them to have high standards of human values and high aspirations for human achievement, including their own." 32 By comparing the virtue of faithfully abiding to contracts with the ability to carefully determine proper "personal relations ... . with respect to race," the PHS framed racial segregation as an honourable virtue. Furthermore, in moving immediately from a brief mention of race to "human values" and "human achievement," the PHS implied that both the "human race" and the "white race" were intimately connected to these measures of worth. Through sex education, high schoolers would learn to discern and aspire to racial relationships that would satisfy these "high standards" of worth, namely, relationships with white partners only.

The responsibility of white women to their race and nation was perhaps most explicitly stated in High Schools and Sex Education's outline of the learning outcomes of the sex education program. A pillar of the informational part of the curriculum was the "elementary principles of heredity: continuing of the germ plasm; the individual as custodian of the race current; choice of mate." 33 This series of topics tied together genetic heredity, responsibility for the continuation of the white race, and the selection of sexual partners. Having learned the science of inheritance, students were to recognize that their duty as "custodians" of the white race was to choose a mate wisely. Again, the implication was that one would fulfil one's duty to strengthen the vitality of the white race by selecting a white partner and producing white children. Evidently, considerations of race, eugenics, and racial purity were a crucial part of the early twentieth century sex education curriculum, and closely intertwined with explanations of the genetic and physical processes of reproduction.

The PHS's 1922 sex education curricular guide referred not only to race in the positive

\footnotetext{
${ }^{31}$ Zimmerman, Too Hot to Handle, 33.

32 PHS, High Schools and Sex Education, 8.

${ }^{33}$ PHS, High Schools and Sex Education, 10.
} 
sense of strengthening the white race, but also as warning against the dangers of mixed race relationships and venereal disease. In the description of lectures on venereal diseases, home economics teachers were advised to introduce the topic "by a general talk on the menace of the three great racial dangers: alcoholism, tuberculosis, and venereal disease." 34 These "racial dangers" threatened the strength of the white race, and should an epidemic become uncontrollable, could spell the downfall of white America. By labelling venereal disease as a "racial danger," the PHS revealed that its concern with the venereal disease epidemic was not only a public health issue for Americans broadly, but also a specific concern for the racial integrity and continued existence of white native-born Americans. White female students in home economics classes across the nation thus carried the responsibility of eradicating venereal disease so as to ensure the continued existence of their race and people. In an era of racist, nativist, and xenophobic anxieties against eastern and southern European immigrants, Asian immigrants, and African Americans, this call to defend white Americanism well-reflected the mood of much of the nation.

When sex education first emerged in American public schools during the early twentieth century, it was in response to a medical epidemic and took place in a context of increasing urbanization, immigration, and women's autonomy. As demonstrated in the U.S. Public Health Service's 1922 recommended sex education curriculum for high school students, High Schools and Sex Education, the federal agency's recommended curriculum emphasized three responsibilities for young women. First, female students were told that they, through their actions, dress, and behaviour, were responsible for the sexual morality and propriety of their male classmates, and even men more broadly. Second, young women's sex education emphasized their role as mothers and wives. Finally, young women learned that they were caretakers of the white race, and that their sexual health, sexual relationships, marriages, and children carried important implications for the continued existence of white America. Sex education for high school students in American public schools during the early twentieth century was thus heavily permeated by the gender, political, social, and cultural motivations and convictions of the educational and public health officials that sought to define what, exactly, sex education should be. In a rapidly changing period in American social, political, and cultural life, these officials cast for young women an out-dated, stereotypical and patriarchal view of their sexuality and their role as women.

${ }^{34}$ PHS, High Schools and Sex Education, 58. 


\section{Bibliography}

Eliot, Charles W. "Defects in American Education Revealed by the War." New York Times, 24 November 1918. [Primary Source]

Lord, Alexandra M. Condom Nation: The U.S. Government's Sex Education Campaign from World War I to the Internet. Baltimore: The Johns Hopkins University Press, 2010.

—. "Naturally Clean and Wholesome': Women, Sex Education, and the United States Public Health Service, 1918-1928." Social History of Medicine 17, no. 3 (December 2004): 423441.

Rury, John L. “'We Teach the Girl Repression, the Boy Expression’: Sexuality, Sex Equity and Education in Historical Perspective." Peabody Journal of Education 64, no. 4 (Summer 1987): 44-58.

United States Public Health Service. High Schools and Sex Education: A Manual of Suggestions on Education Related to Sex. Washington, D.C.: Government Printing Office, 1922. [Primary Source]

Zimmerman, Jonathan. Too Hot to Handle: A Global History of Sex Education. Princeton: Princeton University Press, 2015. 